\title{
Use of a totally implantable system for venous access in cystic fibrosis
}

\author{
R J STEAD, T I DAVIDSON, F R DUNCAN, MARGARET E HODSON, J C BATTEN \\ From the Department of Cystic Fibrosis, Brompton Hospital and Cardiothoracic Institute, and the Academic \\ Surgical Unit, Royal Marsden Hospital, London
}

Pseudomonas aeruginosa is the major bronchopulmonary pathogen affecting adolescents and adults with cystic fibrosis. ${ }^{1}$ It is not susceptible to any oral antimicrobial agents generally available and is conventionally treated with intravenous chemotherapy. In patients requiring frequent or prolonged treatment, however, thrombophlebitis of peripheral veins may necessitate central venous access. We report the use of an implantable means of venous access suitable for use in selected patients with cystic fibrosis.

\section{Methods}

The Port-a-Cath system (Pharmacia) is totally implantable and consists of a silicone catheter attached to a $2.5 \times 1.3 \mathrm{~cm}$ stainless steel chamber with a self sealing injection port. Under local or general anaesthesia, and full aseptic conditions, the catheter is introduced surgically into a central vein and the position of the tip is checked radiographically. Through a second incision lower on the chest wall a subcutaneous pocket for the portal is made by blunt dissection. The catheter is tunnelled subcutaneously and connected to the portal, and the wounds are closed. ${ }^{2}$ Huber needles, which slice through the silicone septum without coring it (fig 1), are used to inject drugs percutaneously into the portal. Between courses of treatment the needle is removed, leaving intact skin overlying the portal.

In the course of eight months the system was implanted in nine patients (eight of them female) with cystic fibrosis; their age range was 13-38 (median 22) years. As percentages of predicted normal ${ }^{3}$ their median (range) $\mathrm{FEV}_{1}$ was $32 \%$ $(17-47 \%)$ and FVC $30 \%(26-62 \%)$. They were all chronically colonised by Pseudomonas aeruginosa, and had required a median of four (range 2-12) hospital admissions for intravenous antimicrobial chemotherapy within the previous year. Peripheral venous access had become unsatisfactory in all of them, and six had required central venous catheterisation. Three patients had diabetes mellitus.

In view of poor respiratory function Port-a-Cath implantation was performed under local anaesthesia in eight patients, but one patient underwent general anaesthesia at her own request. The cephalic vein was cannulated in three patients, the external jugular in five, and the internal jugular vein in one patient. The position of the portal was carefully chosen preoperatively to ensure that it interfered as little as possible with chest physiotherapy. In patients regularly

Address for reprint requests: Dr RJ Stead, Department of Cystic Fibrosis, Cardiothoracic Institute, Brompton Hospital, London SW3 6HP.

Accepted 30 June 1986 undertaking parasternal percussion the portal was sited near the anterior axillary line, and in those performing lateral chest percussion the portal was sited medially.

\section{Results}

Implantation of the system took one to two and a half hours to perform. Postoperative pain was well controlled by oral analgesia in seven patients. In one patient pain around the portal during physiotherapy required pethidine for the first week. In a second patient persistent pain around the portal was relieved by resiting the portal. In a third patient the catheter migrated in the subclavian vein and required repositioning. No wound infection, septicaemia (see Addendum), venous thrombosis, or catheter occlusion has occurred.

In all of the patients the system has been used for antimicrobial chemotherapy, and in eight patients this has been

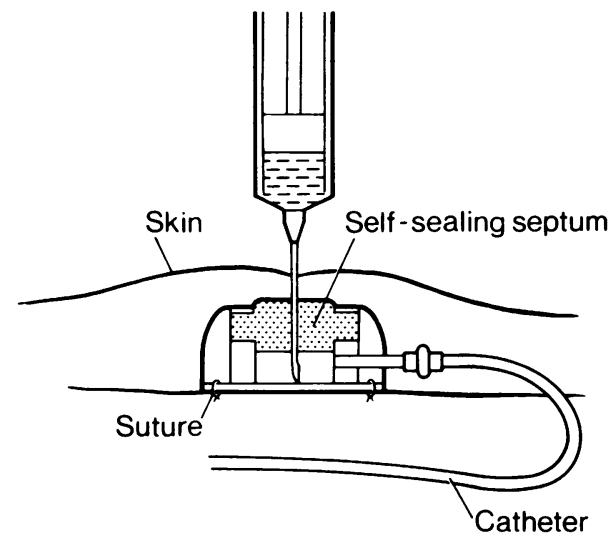

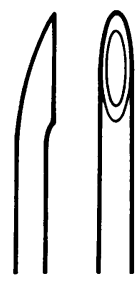

Huber

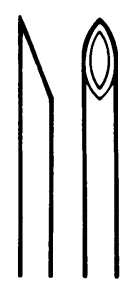

Regular
Fig 1 Diagram of implanted portal and Huber needle (with side aperture). Straight and right angle Huber needles are available in $19 G, 20 G$, and $22 G$ calibre. 


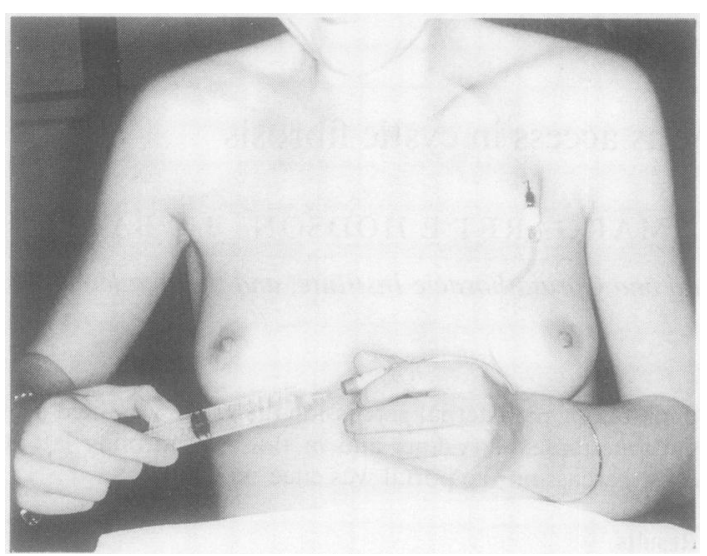

Fig 2 Pationt with astic fihrosis injecting into the sistem through extension tuhing and right angle Huher needle. During treatment the tuhing and needle remain in place and are changed weekly, repeated puncrures thus heing aroided.

given partly at home. After initial instruction, needle insertion and drug administration has been undertaken by the parents of the two youngest patients. The older patients have administered their drugs completely independently (fig 2) after a similar brief period of instruction. In five patients the system has also been used for parenteral nutrition. When the system is in use the Huber needle and extension tube are changed weekly by a nurse or relative with full aseptic technique. The system has functioned for 3-10 months (median 6 months). Two patients have since died of respiratory failure.

\section{Discussion}

Peripheral thrombophlebitis due to intravenous antimicrobial treatment is a common problem in cystic fibrosis and, particularly in female patients, may make venous access difficult. Suitable veins may possibly be preserved by the use of long peripheral catheters, but if these cannot be placed or are unsatisfactory central venous access is required. Central catheters may be introduced surgically or percutaneously, but the latter route carries the risk of pneumothorax, a serious complication in cystic fibrosis. ${ }^{4}$ Central catheters also carry the risk of infection via the skin exit site, and require dressings that must be kept dry. They are unsuitable for domiciliary treatment unless tunnelled (for example, Hickman) catheters are used. ${ }^{5}$

The Port-a-Cath system is initially expensive, costing about $f 300$ ), but has the advantage over percutaneous catheters of being permanent. The silicone septum will withstand over 2000 punctures with the $20 \mathrm{G}$ or $22 \mathrm{G}$ Huber needle (data from manufacturer). The implantable system requires flushing only monthly as opposed to every 48 hours with percutaneous lines. ${ }^{5}$ In all but one of our patients postoperative pain resolved within one week: the pain associated with needle insertions has not been a problem. The migration of the catheter that occurred in one of our patients seems likely to have been related to use of the cephalic vein, and to be preventable by suturing the catheter within the vessel or by alternative use of the external jugular vein."

There is now extensive experience of the use of the Port-a믐 Cath system for long term cancer chemotherapy, ${ }^{n-9}$ witlo excellent acceptance by patients. Use of the system has beer reported in one patient with cystic fibrosis. ${ }^{10}$ a 3 year old girl, in whom the device functioned satisfactorily for five months until her death. Our initial experience of the systens over 51 patient months is encouraging and it appears usefü in carefully selected patients with cystic fibrosis who have unsatisfactory peripheral veins and require frequent intra $\vec{\omega}$ venous treatment. Interference with chest physiotherapy iহ minimal and there is no restriction of the patient's activit芦 when the system is not in use. Generally the results have been cosmetically acceptable, although one woman remain 5 unhappy about the appearance of the portal in the uppef breast (but she is pleased with the improved venous access) $\overrightarrow{0}$ All six patients with previous experience of percutaneous central catheters prefer the implantable system.

We are grateful to Drs JO Warner and RK Knight for perT mission to include three of their patients at Brompton Hos을 pital. Miss Sally Hockley kindly prepared the manuscript. $\frac{\mathrm{C}}{\mathrm{N}}$

\section{References}

1 Batten JC. Matthew DJ. The respiratory system. In: Hodson ME: Norman AP. Batten JC. eds. Cistic fihrosis. Eastbourne: Bail lière Tindall. 1983:105-31

2 Soo KC, Davidson TI. Selby P. Westbury G. Long-term venous access using a subcutaneous implantable drug delivery system $\overline{\bar{O}}$ Ann $R$ Coll Surg Engl 1985:67:263-5.

3 Cotes JE. In: Lung function: assessment and application in mediฐ cine. 4th edition. Oxford: Blackwell Scientific Publications 1979.

4 Penketh ARL. Knight RK. Hodson ME, Batten JC. Manage ment of pneumothorax in adults with cystic fibrosis. Thora. 1982:37:850-3.

5 Sagor G. Mitchenere P. Layfield J. Prentice HG, Kirk RM. Pro longed access to the venous system using the Hickman righ atrial catheter. Ann R Coll Surg Engl 1983:65:47-9.

6 Davidson TI, Soo KC. Totally implantable vascular access fo long-term chemotherapy. Br Med J 1986;292:1016.

7 Meurette J. Depaldt G. Meynadier J. Vascular access for intra venous chemotherapy: totally implanted systems. Eur J Surg Oncol 1985:11:295-8.

8 Bothe A. Piccione W. Ambrosino JJ. Benotti PN. Lokich JJ? Implantable central venous access system. Am $J$ Sur\& 1984:147:565-9.

9 Young AE, Allen DR, Harrop-Griffiths K, Corbett WA, Lam D bert M. Totally implantable vascular access for long-term chemotherapy. Br Med J 1985:291:1608-9.

10 Pattison J, Heaf DP. Totally implantable vascular access in treato ment of cystic fibrosis. Lance' 1986;i:799.

\section{Addendum}

Since this paper was accepted a woman aged 30 years, taking oral corticosteroids, presented with fever one year aftee implantation and was found to have a Candida albicans septicaemia. Her fever resolved on removal of the system and a further Port-a-Cath was implanted two months later There has been no recurrence after four months. 